\title{
DETERMINATION OF FLUORINE AND OF SILICA IN GLASSES AND ENAMELS CONTAINING FLUORINE
}

\author{
By J. I. Hoffman, and G. E. F. Lundell
}

ABSTRACT

Methods for the determination of fluorine and of silica in the presence of each other remain practically the same as those developed by Berzelius over 100 years ago. These methods are very tedious and normally give low results for both fluorine and silica. In the new methods that are described, the procedure for separating silica and alumina from fluorine has been modified so that it is more accurate and takes less time, while the old method of determining fluorine as calcium fluoride has been replaced by the more rapid and equally accurate lead chlorofluoride method.

\section{CONTENTS}

I. Introduction

II. General discussion of methods of analysis 1. Silica

(a) Determination without regard to the effect of fluorine.

(b) The use of boric oxide or arsenic trioxide to prevent loss of silica

(c) The method of Berzelius.

2. Fluorine

(a) Methods involving the volatilization of fluorine as silicon tetrafluoride.

(b) Precipitation as calcium fluoride in the presence of calcium carbonate..............................

(c) Precipitation of calcium fluoride in the presence of calcium oxalate

(d) Volumetric determination of fluorine by titration with ferric chloride.

(e) Other methods..........

III. Recommended methods of analysis

1. Preliminary discussion

(a) Drying the sample........

(b) Fusion of the sample........

(c) Separation of silica from fluorine........

(d) Determination of silica.........

(e) Determination of fluorine

(f) Routine method for fluorine.......

2. Procedures

(a) Fusion of the sample and separation of silica from fluorine........... 591

(b) Determination of silica

(c) Determination of fluorine._. 592

(d) Routine method for fluorine................ 594

IV. Summary _... 595 


\section{INTRODUCTION}

Many methods have been devised for the determination of fluorine in solutions of pure fluorides. Only a few of these can be applied to the analysis of such complex materials as glasses and enamels, and none of them gives satisfactory results. The same can be said concerning the determinations of silica in materials containing fluorine and silica, for silica can not be successfully determined unless it can be satisfactorily separated from fluorine.

\section{GENERAL DISCUSSION OF METHODS OF ANALYSIS}

\section{SILICA}

\section{(a) DETERIINATION WITHOUT REGARD TO THE EFFECT OF FLUORINE}

If an acid solution containing silica and fluorine is evaporated to dryness, some of the silicon is lost by volatilization as silicon tetrafluoride, $\mathrm{SiF}_{4}$. The loss of silicon can not be calculated even if the quantity of fluorine present is exactly known because the loss varies with conditions and the amount that is lost is always less than that which is equivalent to the fluorine. Losses are greater in open than in covered vessels. Table 1 shows results that were obtained in determinations of silica in which the effect of fluorine was disregarded.

TABLE 1.-Determination of silica without regard to the effect of fluorine ${ }^{1}$

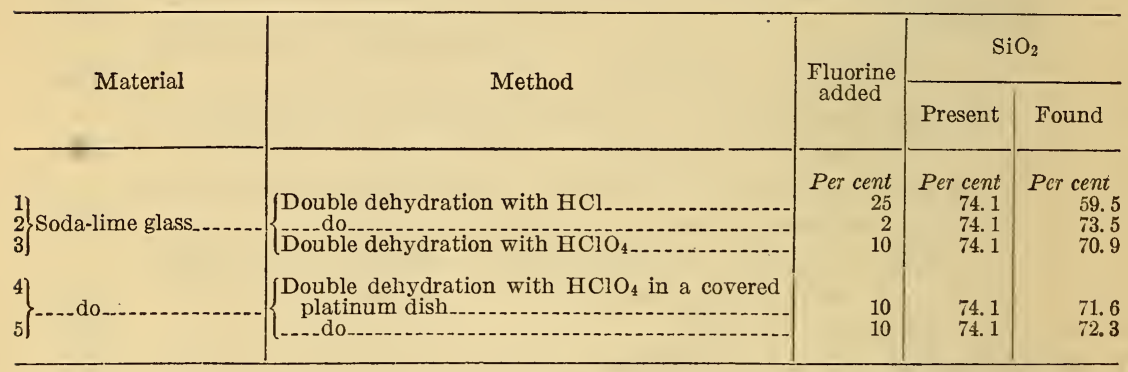

1 The exact amounts of silica and fluorine in this case as well as in those to be mentioned in subsequent sections of this paper were known because the substances analyzed were synthetic mixtures of materials of known silica or fluorine content. The silica was usually added as Bureau of Standards soda-lime glass No. 80 and the fluorine as calcium fluoride of known purity or as sodium fluoride made by a modification of the method employed by D. J. McAdam and E. F. Smith (J. Am. Chem. Soc., 3s, p. 592; 1912) in their atomic weight work. In their method the hydrochloric acid in the hydrofluoric acid is removed by distilling from a solution containing an excess of potassium permanganate and discarding the first part of the distillate which contains the chlorine. In our work a purer hydrofluoric acid was obtained by adding about $0.5 \mathrm{~g}$ each of potassium fluoride and silver sulphate to $500 \mathrm{ml}$ of a reasonably pure solution of hydrofluoric acid and distilling in a platinum still. The potassium fluoride "fixes" the silica as potassium fluosilicate, $\mathrm{K}_{2} \mathrm{SiF}_{6}$, and the silver sulphate forms insoluble silver chloride which is not decomposed in the distillation. The first $25 \mathrm{ml}$ of distillate and the last $100 \mathrm{ml}$ portion remaining in the still should be discarded. One such distillation yields hydrofluoric acid which is entirely free from hydrochloric acid and silica.

(b) THE USE OF BORIC OXIDE OR ARSENIC TRIOXIDE TO PREVENT LOSS OF SILICA

P. Jannasch and H. Weber ${ }^{1}$ state that it is probable that if a fluorine-bearing silicate is fused with boric oxide at the temperature

1 Ber. Deutsch. Chem. Gesell., 32, p. 1670; 1899. 
of the oxygen blast, all of the fluorine is volatilized as boron trifluoride, $\mathrm{BF}_{3}$, without any loss of silica. All attempts on our part to verify this statement yielded low results for silica, but it is not certain whether silica was lost during the fusion or whether fluorine was incompletely volatilized and caused a loss of silica during the subsequent evaporation of the acidified solution. Silica is also lost if the determination is made by fusing with sodium carbonate, adding boric acid to the solution of the melt, and dehydrating with hydrochloric acid. Furthermore, if boric acid is present during the dehydration, the silica is always strongly contaminated by it, and treatment with methyl alcohol and hydrochloric acid does not entirely remove it. If it is not removed, it will count as silica for it is also volatilized by treatment with hydrofluoric acid.

The use of arsenious acid for the purpose of volatilizing the fluorine as arsenious fluoride, $\mathrm{AsF}_{3}$, also yields incorrect results, for it was found not to prevent the formation of some silicon tetrafluoride, and the silica that is obtained is strongly contaminated by arsenic.

\section{(c) THE METHOD OF BERZELIUS}

The method of Berzelius ${ }^{2}$ has stood for over 100 years and is still regarded as the standard procedure for separating silica from fluorine. It is long and tedious and gives results that are fairly accurate but usually low. The chief steps are as follows: The sample is decomposed by fusing with a mixture of sodium and potassium carbonates, the melt is extracted with water, the solution filtered, and the alumina and part of the silicic acid are separated from the fluorine in the water extract by precipitating with ammonium carbonate. The solution is then filtered and the rest of the silica removed by nearly neutralizing with successive small additions of nitric acid, boiling with an ammoniacal solution of zinc oxide, and filtering. The fluorine is determined in the filtrate by precipitating it as calcium fluoride. The silica is determined by evaporating to dryness the acid solution of the three residues (the water insoluble, the precipitate produced by ammonium carbonate, and that produced by the ammoniacal solution of zinc oxide). The precipitation with ammonium carbonate requires 12 hours, and the precipitate (if much silica is present, as in glasses) is extremely difficult to filter and wash. The subsequent neutralization with nitric acid, preparatory to the precipitation of the last of the silica by means of an ammoniacal solution of zinc oxide, is also time consuming, and the slightly alkaline filtrate obtained at the end of the operation usually holds from 1 to $2 \mathrm{mg}$ of silica. In the analysis of a glass containing 9 per cent of fluorine an average of 73.6 per cent of silica was obtained by this method as compared with 74.1 per cent present. (See footnote under Table 1, p. 594.) 
The use of mercuric oxide in preparing the precipitating reagent as recommended by $\mathrm{F}$. Seemann ${ }^{3}$ for recovering the last of the silica yields results which are slightly lower than those obtained when zinc oxide is used, even if the filtrate is neutralized and again evaporated as directed by Seemann. Moreover, the last of the mercury is not easily expelled from large silica residues.

\section{FLUORINE}

(a) METHODS INVOLVING THE VOLATILIZATION OF FLUORINE AS SILICON TETRAFLUORIDE

Glasses and enamels can not be decomposed by direct treatment with sulphuric or perchloric acid. It is obvious that methods involving the volatilization of fluorine as silicon tetrafluoride are impractical if a preliminary fusion is required to bring the material into solution. Even with soluble materials not all of the fluorine can be recovered by such a distillation. D. S. Reynolds, W. H. Ross, and K. D. Jacob ${ }^{4}$ have shown that 92 per cent is about all that can be obtained by the best available procedures.

\section{(b) PRECIPITATION AS CALCIÜM FLUORIDE IN THE PRESENCE OF CALCIUM} CARBONATE

It is practically impossible to filter freshly precipitated calcium fluoride. In the Berzelius method calcium fluoride is thrown down in neutral solution, together with some calcium carbonate. The mixture of these two precipitates can be filtered, but the fluoride must then be separated from calcium carbonate. This is done by first igniting at a low heat to get the fluoride into granular form and then treating the mixture with dilute acetic acid to leach out the carbonate. As many as four extractions with the dilute acetic acid are sometimes required. This always causes some solution of the fluoride, and a correction must be made for the amount that is dissolved. A further difficulty is caused by the presence of phosphates, vanadates, chromates, aluminum, and ammonium salts. All of these must be removed from the solution before the precipitation. The procedure will yield fairly accurate results, but it is long and tedious and requires strict attention to details. In the analysis of two glasses containing 9.93 and 5.75 per cent of fluorine (added as calcium fluoride), 9.74 and 5.77 per cent, respectively, were obtained by this method when all recoveries and solubility corrections were made.

(c) PRECIPITATION OF CALCIUM FLUORIDE IN THE PRESENCE OF CALCIUM OXALATE ${ }^{3}$

The coprecipitation of calcium fluoride and calcium oxalate is similar in many respects to the preceding method except that a known

${ }^{3} \mathrm{Z}$. anal. Chem., 44, p. 343; 1905.

4J. Assoc. Official Agri. Chem., 11, pp. 225-236; 1928.

B G. Starck and E. Thorin, Z. anal. Chem., 51, p. 14; 1912. 
quantity of a soluble oxalate is added instead of an unknown quantity of carbonate. The mixed precipitate is filtered, dried, and weighed, and the quantity of calcium fluoride is obtained by subtracting the weight of calcium oxalate equivalent to the amount of oxalate added. The precipitate is extremely difficult to filter and wash, but if this can be accomplished fairly accurate results are obtained, and the troublesome leaching with acetic acid is not required. In the analysis of two glasses containing 9.80 and 5.75 per cent of fluorine (added as calcium fluoride), 9.62 and 5.72 per cent, respectively, were obtained by this method.

\section{(d) VOLUMETRIC DETERMINATION OF FLUORINE EY TITRATION WITH FERRIC} CHLORIDE 6

Titration of fluorine with a standard solution of ferric chloride involves the precipitation of iron cryolite, $\mathrm{Na}_{3} \mathrm{FeF}_{6}$, in a solution containing alcohol, a soluble fluoride, and a large excess of sodium chloride. Potassium thiocyanate is used as internal indicator. The chief objections to this method are the difficulty of judging the end point and the fact that practically all other substances except fluorine and sodium salts must be absent. An additional drawback is that 1 atom of iron is equivalent to 6 atoms of fluorine.

\section{(e) OTHER METHODS}

In our hands attempts to precipitate fluorine as barium fluosilicate, $\mathrm{BaSiF}_{6}$, proved unsatisfactory because mixtures of barium fluoride and barium fluosilicate were precipitated. Attempts to precipitate thorium fluoride, $\mathrm{ThF}_{4}$, were also unsatisfactory because mixtures of thorium fluoride and sodium thorium fluoride, $\mathrm{Na}_{2} \mathrm{ThF}_{6}$, were precipitated. This is in agreement with the observations of Adolph. ${ }^{7}$ An attempt to precipitate fluorine as $\mathrm{UF}_{4}$ by means of an excess of uranous sulphate (or chloride) also failed. The most promising of the methods used in the preliminary trials was that in which the fluorine is precipitated as lead chlorofluoride, $\mathrm{PbClF}$. This method will be described in detail under methods of analysis.

\section{RECOMMENDED METHODS OF ANALYSIS}

\section{PRELIMINARY DISCUSSION}

After a careful consideration of the methods already described, it was decided that the Berzelius method or some modification of it would be the best for the separation of silica from fluorine. In the methods to be described the long precipitation period with ammonium

${ }^{6}$ See P. Guyot, Compt. rend., 71, p. 274; 1870; and A. Greeff, Ber., 46, p. 2511; 1913.

7 In The Quantitative Methods for Fluorine, Thesis, University of Pennsylvania (1915) and Z. anal. Chem., 55, p. 395; 1916: William H. Adolph gives a good account of a critical study of methods for the determination of fluorine.

$69882^{\circ}-29-6$ 
carbonate, the difficult filtration of the precipitate, and the troublesome neutralization of the sodium carbonate are eliminated in the operations designed for the separation of silica from fluorine. Instead of precipitating the fluorine as calcium fluoride, it is precipitated as lead chlorofluoride which can be weighed or preferably, in this case, dissolved and the chlorine titrated.

\section{(a) DRYING OF THE SAMPLE}

Like most finely powdered substances glasses and enamels absorb some water upon standing in a moist atmosphere, but they offer little difficulty in drying or weighing. A sample ground to pass a No. 80 sieve and dried for one hour at $105^{\circ}$ to $110^{\circ} \mathrm{C}$. is satisfactory.

\section{(b) FUSION OF THE SAMPLE}

All of the orindary glasses and enamels are easily decomposed by fusing them at a moderate heat with sodium or potassium carbonate or a mixture of both. Silica need not be added to aid in the decomposition as the materials under discussion already contain enough. The use of the blast lamp is unnecessary, and even the full heat of the Tirrill burner is seldom required. It is only necessary that the mass be fluid, and it is preferable not to heat much beyond the temperature at which it melts. We have had no evidence of loss of fluorine during the fusion. ${ }^{8}$

Materials containing much silica, together with elements which form insoluble carbonates, as, for example, calcium, magnesium, or lead, when fused with sodium carbonate yield a cake which is quite difficult to disintegrate with hot water. This is especially true of many enamel mixtures. Potassium carbonate melts dissolve more readily, as has been pointed out in a discussion of the analysis of fluorspar, ${ }^{9}$ and are entirely satisfactory.

Occasionally not all of the fluorine is recovered by extracting the melt with water, filtering, and washing the residue. In the present work very few of the residues showed as much as $1 \mathrm{mg}$ of fluorine. To assure complete extraction Hillebrand ${ }^{10}$ recommends that the insoluble residue be ignited and that the fusion and extraction be repeated. F. G. Hawley ${ }^{11}$ recommends that the insoluble residue be boiled with a strong solution of sodium carbonate and then filtered to extract the last of the fluorine. This latter procedure is simple and entirely satisfactory if the original fusion was properly carried out. This treatment of the insoluble residue seldom yields appreciable amounts of fluorine and is only a precautionary measure.

\footnotetext{
${ }^{8}$ F. G. Hawley (Ind. Eng. Chem., 18, p. 573; 1926) found a considerable loss of fluorine when $\mathrm{FeS}_{2}$ was present, but this must have been caused by roasting the sample of $\mathrm{CaF}_{2}$ with $\mathrm{FeS}_{2}$. In such a case sulphur is oxidized to sulphite or sulphate which replaces fluorine.

G. E. F. Lundell and J. I. Hoffman, B. S. Jour. Research, 2, p. 671; 1929.

10 The Analysis of Silicate and Carbonate Rocks, U. S. Geol. Surv. Bull. No. 700.

11 See footnote 8.
} 
(c) SEPARATION OF SILICA FROM FLUORINE

When a sample of glass or enamel is fused with alkali carbonate, extracted with water, and filtered, some of the silica usually remains in the insoluble residue, but most of it passes into the filtrate with the fluorine, from which it must then be separated. In the methods usually employed aluminum and much of the silica are precipitated by adding ammonium carbonate to the solution, allowing it to stand for at least 12 hours, and filtering. The precipitate is very difficult to handle and often requires two or three hours to filter. The addition of large quantities of macerated paper does not materially expedite the filtration. It was found that an entirely satisfactory precipitate can be obtained in a few minutes by adding enough of a nitric acid solution of zinc nitrate to reduce the concentration of the sodium carbonate in the solution to about 1 per cent. The precipitate is bulkier than that obtained in the old method, but it is free from fluorine, contains nearly all of the silica and alumina, ${ }^{12}$ and, above all, it is easily filtered and washed. The silica which still remains in solution is precipitated by neutralizing with nitric acid and boiling with an ammoniacal solution of zinc oxide.

Neutralization by successive small additions of nitric acid (as in the old method) is unnecessarily lengthy and troublesome and leaves the solution slightly alkaline, because not all of the sodium bicarbonate formed is destroyed. Such a solution usually holds from 1 to $2 \mathrm{mg}$ of silica, and it is probably for this reason that most results for silica by the Berzelius method are low. By neutralizing the solution with dilute nitric acid until methyl red changes to a very delicate pink ( $\mathrm{pH}$ about 5.6), and then boiling with a large excess of an ammoniacal solution of zinc oxide, all of the silica is recovered, and no fluorine is lost. A variation of $1 \mathrm{ml}$ of $N$ acid or alkali in this neutralization results in the loss of approximately $1 \mathrm{mg}$ of silica regardless of whether fluorine is present or not. This is true because zinc silicate is soluble in solutions that are alkaline or contain ammonium salts. A little excess of nitric acid would be neutralized with ammonium hydroxide and leave its equivalent of ammonium nitrate in solution.

The use of mercuric oxide instead of zinc oxide as recommended by Seemann ${ }^{13}$ yields slightly low results for silica even if the solution is strictly neutral to methyl red and no fluorine is present. The presence of fluorine has little or no effect on the precipitation whether zinc oxide or mercuric oxide is used. Greater losses of silica occur if the acidity or alkalinity of the solution is increased beyond the point of neutrality to methyl red before adding the ammoniacal solution of mercuric oxide.

${ }^{12}$ In a $0.5 \mathrm{~g}$ sample of glass containing 74 per cent of silica and 6 per cent of alumina, all but 8 per cent of the silica and $0.4 \mathrm{mg}$ of the alumina were removed in this precipitation. The amount of silica left in solution varies somewhat but seldom is greater than that mentioned.

13 See footnote 3, p. 596. 
The results obtained by the different procedures for the recovery of small quantities of silica in the presence of fluorine are shown in Table 2. The precipitates obtained by the use of the zinc oxide reagent were dissolved in sulphuric acid and the silica determined by double dehydration as usual. The precipitates obtained by the use of the mercuric oxide reagent were directly ignited as recommended by Seemann. The weight of silica was then determined by treatment with hydrofluoric and sulphuric acids as usual. Seemann's directions do not clearly define the conditions of the solution prior to adding the ammoniacal solution of mercuric oxide, and it is possible that by proper adjustment of acidity or other conditions, the unfavorable results shown in Table 2 might be improved.

TABLE 2.-Recovery of small quantities of silica in the presence of fluorine

\begin{tabular}{|c|c|c|c|c|c|c|}
\hline & \multirow{2}{*}{ Method of separating silica } & \multirow{2}{*}{$\begin{array}{l}\text { Fluor- } \\
\text { ine } \\
\text { present }\end{array}$} & \multirow{2}{*}{$\begin{array}{l}\text { Other sub- } \\
\text { stances } \\
\text { present }\end{array}$} & \multirow{2}{*}{$\begin{array}{l}\text { Condition of the solution in } \\
\text { which silica was precipitated }\end{array}$} & \multicolumn{2}{|c|}{ Silica } \\
\hline & & & & & Present & Found \\
\hline \multirow[t]{2}{*}{1} & Boilin & $g$ & g & \multirow{2}{*}{ Faint pink to methyl red (pH } & $\stackrel{g}{g}$ & 0.0186 \\
\hline & sol & \multirow{5}{*}{$\begin{array}{l}0.10 \\
.05 \\
.05 \\
.10\end{array}$} & & & \multirow{5}{*}{$\begin{array}{l}.0549 \\
.0737 \\
.0711 \\
.0228 \\
.0204\end{array}$} & \multirow{5}{*}{$\begin{array}{l}.0544 \\
.0730 \\
.0713 \\
.0230 \\
.0193\end{array}$} \\
\hline 3 & 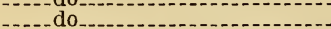 & & $0.1 \mathrm{~g} \mathrm{~B}_{2} \mathrm{O}_{3}$ & do & & \\
\hline 4 & ... & & & do..... do & & \\
\hline 5 & - do & & $0.1 \mathrm{~g} \mathrm{~B}_{2} \mathrm{O}_{3}$ & do & & \\
\hline 6 & ....do.. & & & \multirow{4}{*}{$\begin{array}{l}\text { Neutral to methyl red, then } \\
\text { added } 1 \text { ml N-Na } \mathrm{NO}_{3} \text {. } \\
\text { Between blue and } \mathrm{yellow} \text { of } \\
\text { brom phenol blue (pH } 3.4) \text {. } \\
\text { Faint pink to methyl red (pH } \\
5.6 \text {. }\end{array}$} & & \\
\hline 7 & ....do_- & \multirow{5}{*}{.10} & & & .0269 & \multirow{3}{*}{$\begin{array}{l}.0244 \\
.0055\end{array}$} \\
\hline 8 & Evaporating to dryness with & & & & .0084 & \\
\hline & $\begin{array}{l}\text { oniacal solution of } \\
\text { oxide. }\end{array}$ & & & & \multirow{3}{*}{$\begin{array}{l}.0126 \\
.0115\end{array}$} & \\
\hline $\begin{array}{r}9 \\
10\end{array}$ & -...-do. & & & $-d_{0}$ & & \multirow{2}{*}{.0101} \\
\hline & & & & $\begin{array}{l}\text { Neutral to methyl red then } \\
\text { added } 1 \mathrm{ml} \text { of } \mathrm{N}-\mathrm{Na}_{2} \mathrm{CO}_{3} \text {. }\end{array}$ & & \\
\hline
\end{tabular}

(d) DETERMINATION OF SILICA

- In the Berzelius method silica is determined by dissolving the insoluble residue and the ammonium carbonate and zinc oxide precipitates in hydrochloric acid and dehydrating in the usual manner. In the method to be outlined the residue and the two zinc precipitates are treated in like manner. If an appreciable amount of silica is present, yielding a bulky residue, the first dehydration with hydrochloric acid is easily accomplished on the steam bath. In the second dehydration not much silica is present, and the large quantity of zinc chloride forms a sirup which must be dehydrated on the hot plate. In the absence of large quantities of lead, calcium, or other substances which would form insoluble sulphates, it is preferable to substitute sulphuric acid in the second dehydration. Perchloric acid may be used in any case, but then the dehydration should be made in glass and 2 to $5 \mathrm{ml}$ of nitric acid should be added to oxidize bits of filter paper or other reducing substances which might otherwise react violently with perchloric acid. However, hydrochloric 
acid is decidedly to be preferred in the first dehydration ${ }^{14}$ and sulphuric acid in the second.

Less than $1 \mathrm{mg}$ of silica should escape the second dehydration, and this can be recovered by adding about $0.05 \mathrm{~g}$ of aluminum (as chloride) to the filtrate, precipitating with ammonium hydroxide, dissolving the precipitate in sulphuric acid, evaporating until fumes of the acid appear, diluting, and filtering. Sufficient ammonium chloride must be added to hold zinc in solution during the precipitation with ammonium hydroxide.

\section{(e) DETERMINATION OF FLUORINE}

The determination of fluorine in the filtrate from which the last of the silica has been removed by precipitation with an ammoniacal solution of zinc oxide is most satisfactorily made by precipitating the fluorine as lead chlorofluoride, $\mathrm{PbClF}$. If obtained from pure solutions this precipitate may be collected on an asbestos pad, dried at $140^{\circ}$ C., and weighed. In practice it is usually preferable to dissolve it in dilute nitric acid and determine the chlorine as in Volhard's method because the coprecipitation of small quantities of phosphates, chromates, sulphates, lead carbonate, and the like causes high results if the precipitate is weighed but has little or no effect if the chlorine is titrated. The precipitate is granular, settles very readily, and is easily filtered. Its solubility in water ${ }^{15}(0.325 \mathrm{~g}$ per liter at $20^{\circ}$ C.) upon first consideration might seem to bar its use in quantitative work, but satisfactory results are obtained if it is washed with a saturated solution of the salt. A precipitate washed with a saturated solution of lead chlorofluoride and cold water as described in the method below lost only $0.0024 \mathrm{~g}$, corresponding to less than $0.2 \mathrm{mg}$ of fluorine.

The composition of this precipitate can be varied by changing the conditions of precipitation, but C. Sandonnini ${ }^{16}$ has shown by thermal analysis that lead chlorofluoride is a true compound and not a mixture of $\mathrm{PbF}_{2}$ and $\mathrm{PbCl}_{2}$. Precipitates of the proper composition may be obtained by balancing such variables as volume and acidity of the solution, concentration of lead and chloride ions, temperature, time of standing, etc. The conditions prescribed in the method below are not the only ones which might yield correct results. For instance, higher concentrations of lead and chloride ions, together with higher acidity may yield equally accurate results. Most analysts ${ }^{17}$ differ as to these conditions. Those prescribed in this

\footnotetext{
${ }_{14}$ Large quantities of silica obtained by dehydrating with sulphuric or perchloric acid under the conditions which obtain in this dehydration hold carbon very tenaciously upon ignition. The reason is not apparent, but it is extremely difficult to obtain silica which is white. Slow ignition in the beginning is essential.

15 G. Starck, Z. anorg. Chem., 70, p. 173; 1911.

${ }^{16}$ Atti. R. Accad. Lincei, 20, p. 172; 1911.

17 See reference in footnote 8 , p. 598, and footnote 15, above; also L. D. Hammond, Ind. Eng. Chem., 16, p. $938 ; 1924$.
} 
paper can be duplicated easily by different operators. Reasonable duplication is necessary for correct results. For example, the lead nitrate and sodium acetate should be weighed to $0.1 \mathrm{~g}$. The $\mathrm{pH}$ value of the solution after adding the sodium acetate is about 5 . At this acidity fluorine causes no trouble, and glass vessels may be used for the precipitation.

The presence of aluminum, iron, large quantities of alkali salts, and boric oxide retard or prevent the complete precipitation of lead chlorofluoride. Of these, the first two are by far the most troublesome, probably because they form cryolites which are more stable than lead chlorofluoride. The effect of the last two can be minimized by letting the solution stand for a longer time and is not serious with the quantities usually encountered in the analysis of glasses and enamels. Boron has a greater effect when the quantity of fluorine is large than when it is small. In the method to be described; the effect is small and can usually be disregarded in the analysis of glasses or enamels if the amount of fluorine involved lies between 0.01 and $0.03 \mathrm{~g}$. Above $0.03 \mathrm{~g}$ its effect becomes more noticeable. The effect of these substances is shown in Table 3.

TABLE 3.-Determination of fluorine in synthetic solutions by precipitation as $\mathrm{PbClF}$ and titration of chlorine

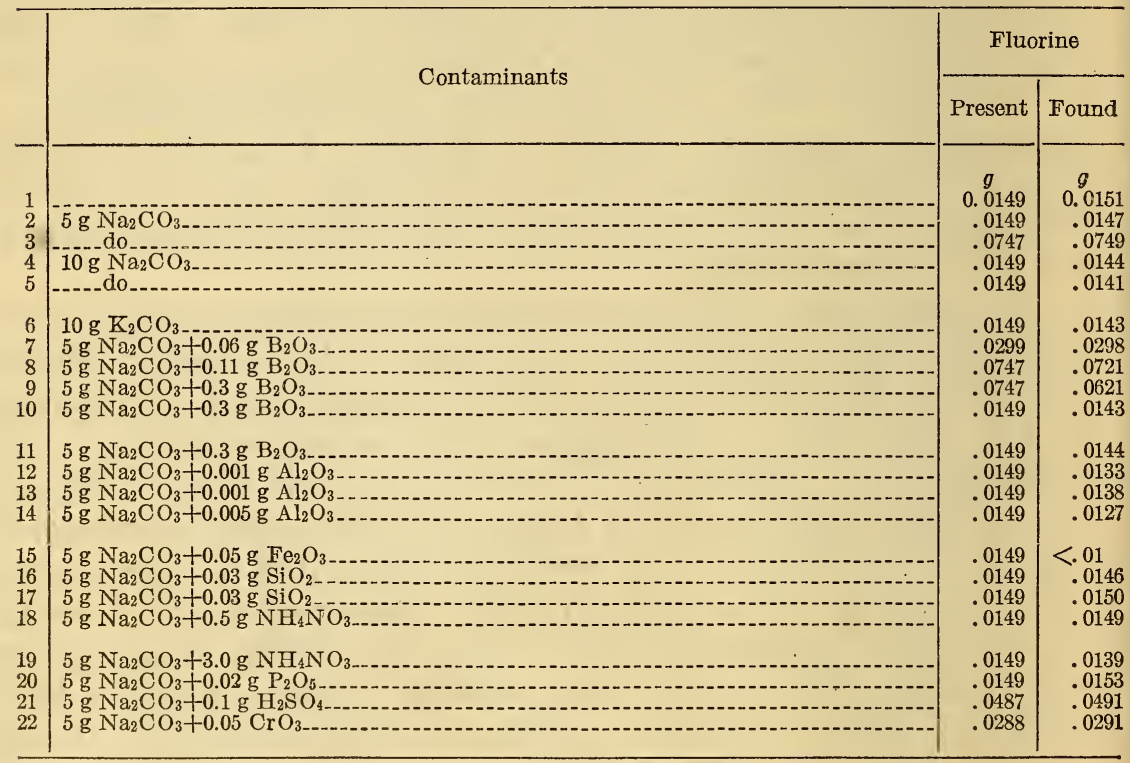

The results in Table 3 were obtained by direct determinations in synthetic solutions by procedure $(c)$ below and did not involve a preliminary fusion. It is apparent that small quantities of silica, ammonium nitrate, phosphoric acid, sulphuric acid, and chromic acid 
have little or no harmful effect if lead chlorofluoride is precipitated under the conditions prescribed, and the chlorine is titrated as in Volhard's method. Phosphates, sulphates, and chromates are precipitated, at least in part, with lead chlorofluoride but are harmful only so far as they may carry down chlorides. The positive error from this source is apparently slight. Lead phosphate if thrown down with lead chlorofiuoride, creeps through the filter, but this has no effect upon the result.

\section{(f) ROUTINE METHOD FOR FLUORINE}

If fluorine alone is to be determined, the careful separation of silica from fluorine need not be made, and the time required for a fluorine determination can be materially reduced by omitting the digestion of the first insoluble residue and the precipitation with ammoniacal zinc oxide solution. Such a modification is described in procedure (d) below.

\section{PROCEDURES}

(a) FUSION OF THE SAIMPLE AND SEPARATION OF SILICA FROM FLUORINE

Fuse $0.5000 \mathrm{~g}$ of the sample (dried at $105^{\circ} \mathrm{C}$.) with $5 \mathrm{~g}$ of sodium or potassium carbonate or a mixture of both, leach the cooled melt with hot water, and filter when disintegration is complete. Return the insoluble residue to the dish by the use of a jet of water, add $50 \mathrm{ml}$ of a 2 per cent solution of sodium carbonate, boil for a few minutes, filter, and wash thoroughly with hot water. ${ }^{18}$ Reserve the residue (1) for the determination of silica. To the combined filtrates, which should have a volume of approximately $300 \mathrm{ml}$, add $1 \mathrm{~g}$ of zinc oxide dissolved in $20 \mathrm{ml}$ of dilute nitric acid (1:9), ${ }^{19}$ boil for one minute, filter, and wash the residue thoroughly with hot water. Reserve the precipitate (2) for the determination of silica. Add a few drops of methyl redindicatorsolution to the filtrate, nearly neutralize with nitric acid, and evaporate to a volume of $200 \mathrm{ml}$, taking care that the solution remains alkaline during the evaporation. Finish the neutralization of the concentrated solution by adding dilute nitric acid (1:9) until the color is a very faint pink. Now add $1.0 \mathrm{~g}$ of zinc oxide dissolved in ammonium hydroxide and ammonium carbonate, ${ }^{20}$ and boil in a covered platinum dish until the odor of ammonia is entirely gone. This usually requires boiling until the volume of the solution has been reduced to about $50 \mathrm{ml}$. After all of the ammonia is expelled,

\footnotetext{
${ }_{18}$ Boiling with a solution of scdium carbonate aids in completely extracting the fluorine from the insoluble residue, but is not necessary in routine work if the melt has been well disintegrated at the start.

19 This denotes $10 \mathrm{ml}$ of nitric acid (sp. gr. 1.42) mixed with $90 \mathrm{ml}$ of water. This system of designating dilute acids is used throughout this paper. If no dilution is specified, the concentrated reagent is intended.

20 Transfer $1.0 \mathrm{~g}$ of zinc oxide and $2.0 \mathrm{~g}$ of ammonium carbonate to a small beaker, add $20 \mathrm{ml}$ of water and $2 \mathrm{ml}$ of ammonium hydroxide (sp. gr. 0.90), and digest on the steam bath until a clear solution is obtained.
} 
add about $50 \mathrm{ml}$ of warm water, stir, allow to stand for a few minutes, filter, and wash the precipitate (3) with cold water. Reserve the filtrate (4).

\section{(b) DETERMINATION OF SHICA}

With the aid of a jet of dilute hydrochloric acid $(5: 95)$ transfer the insoluble residue (1) and the two zinc precipitates (2 and 3) from the papers to the dish in which the last precipitation was made. Ignite all papers used in the preceding filtrations, and add any residue so obtained to the contents of the dish. Now add $25 \mathrm{ml}$ of hydrochloric acid and evaporate to dryness on the steam bath. Remove the dish from the steam bath, drench the residue with $10 \mathrm{ml}$ of hydrochloric acid, and then add 100 to $150 \mathrm{ml}$ of hot water. Digest on the steam bath for 15 minutes, filter, and wash thoroughly with hot dilute hydrochloric acid (5:95) and then with hot water. Return the filtrate and washings to the dish in which the evaporation was made, add $10 \mathrm{ml}$ of sulphuric acid, ${ }^{21}$ and evaporate until fumes of sulphuric acid are evolved. Allow to cool, add 100 to $150 \mathrm{ml}$ of warm water, digest for a few minutes until salts are in solution, filter, and wash with hot water. Place the two papers containing the silica in a weighed platinum crucible, heat slowly until dry, next char the paper without inflaming, burn off the carbon at as low a temperature as possible, and finally ignite at about $1,200^{\circ} \mathrm{C}$. Cool in a desiccator, weigh, and repeat the heating until a constant weight is obtained. Determine the silica by treatment with hydrofluoric and sulphuric acids in the usual manner.

To recover the silica left in the filtrate after the second dehydration, add about $0.05 \mathrm{~g}$ of aluminum (in the form of chloride) and 10 to $15 \mathrm{~g}$ of ammonium chloride, and precipitate the aluminum with ammonium hydroxide. Filter and dissolve the precipitate in 50 $\mathrm{ml}$ of dilute sulphuric acid (1:9), dehydrate, filter, and add the small quantity of silica to that obtained above. ${ }^{22}$

\section{(c) DETERMINATION OF FLUORINE}

To the filtrate (4) add two drops of brom phenol blue ${ }^{23}$ indicator and $3 \mathrm{ml}$ of a 10 per cent solution of sodium chloride. Adjust the volume of the solution to $250 \mathrm{ml}$, add dilute nitric acid until the color changes to yellow, and then add dilute sodium hydroxide until it

\footnotetext{
${ }^{21} 25 \mathrm{ml}$ of 60 to 70 per cent perchloric acid may be substituted for the sulphuric acid, but then 2 to $5 \mathrm{ml}$ of nitric acid should be added and the dehydration carried out in glass.

${ }_{22}$ This recovery usually amounts to less than $1 \mathrm{mg}$ of silica and may be omitted in routine work if the previous operations have been properly performed.

${ }^{23}$ To prepare the brom phenol blue indicator solution grind the dry powder thoroughly with a sodium hydroxide solution ( $1.5 \mathrm{ml}$ of $0.1 \mathrm{~N}$ sodium hydroxide for $0.1 \mathrm{~g}$ of powder) and dilute to make a 0.4 per cent solution.
} 
changes just to blue. Now add $2 \mathrm{ml}$ of dilute hydrochloric acid $(1: 1)$ and $5.0 \mathrm{~g}$ of solid lead nitrate, $\mathrm{Pb}\left(\mathrm{NO}_{3}\right)_{2}$, and heat on the steam bath. As soon as the lead nitrate is in solution, add $5.0 \mathrm{~g}$ of solid. sodium acetate, ${ }^{24} \mathrm{NaC}_{2} \mathrm{H}_{3} \mathrm{O}_{2}+3 \mathrm{H}_{2} \mathrm{O}$, stir vigorously, and digest on the steam bath for one-half hour with occasional stirring. Allow to stand over night ${ }^{25}$ at room temperature and decant the solution through a paper of close texture (No. $589 \mathrm{~S}$ and S blue band or No. 42 Whatman). Wash the precipitate, beaker, and paper once with cold water, then four to five times with a cool saturated solution of lead chlorofluoride ${ }^{26}$ and then once more with cold water.

Transfer the precipitate and paper to the beaker in which the precipitation was made, stir the paper to a pulp, add $100 \mathrm{ml}$ of dilute nitric acid (5:95), and heat on the steam bath until the precipitate is dissolved (five minutes is ample). Then add a slight excess of a $0.2 \mathrm{~N}$ solution of silver nitrate, ${ }^{27}$ digest on the steam bath for onehalf hour, cool to room temperature while protected from the light, filter, wash with cold water, and determine the silver nitrate in the filtrate by means of a standard solution of potassium thiocyanate, ${ }^{28}$ using $5 \mathrm{ml}$ of a solution of ferric alum as the indicator. ${ }^{29}$ Subtract the amount of silver nitrate found in the filtrate from that originally added. The difference will be that required to combine with the chlorine in the lead chlorofluoride, and from this the fluorine may be computed. One $\mathrm{ml}$ of $0.2 \mathrm{~N}$ silver nitrate is equivalent to $0.00380 \mathrm{~g}$ of fluorine.

The method as written holds well between the limits of 0.01 to $0.1 \mathrm{~g}$ of fluorine. Below $0.01 \mathrm{~g}$ the results have a tendency to be slightly low and above $0.1 \mathrm{~g}$ they tend to be slightly high.

Typical results obtained by the method are shown in Table 4.

\footnotetext{
24 If a good grade of sodium acetate is not availablc, prepare a solution as follows: Add $300 \mathrm{~g}$ of sodium bicarbonate to about $205 \mathrm{ml}$ of glacial acetic acid, dilute to about $500 \mathrm{ml}$ with water, and heat on the steam bath until frothing ceases. Cool the solution, and dilute it to 1 liter. The final solution should give an acid reaction with methyl red. $10 \mathrm{ml}$ of this solution is equivalent to approximately $5 \mathrm{~g}$ of sodium acetate, $\mathrm{NaC}_{2} \mathrm{H}_{3} \mathrm{O}_{2}+3 \mathrm{H}_{2} \mathrm{O}$.

${ }^{26}$ Four hours is sufficient in routine work unless much boron is present.

${ }_{26}$ To prepare lead chlorofluoride wash solution: (a) Dissolve $10 \mathrm{~g}$ of lead nitrate in $200 \mathrm{ml}$ of water; (b) dissolve $1.0 \mathrm{~g}$ of sodium fluoride in $100 \mathrm{ml}$ of water and add $2 \mathrm{ml}$ of concentrated hydrochloric acid; and, (c) mix solutions $(a)$ and $(b)$. Allow the precipitate to settle and decant the supernatant liquid. Wash four or five times with $200 \mathrm{ml}$ of water by decantation, and then add about 1 liter of cold water to the precipitate and allow to stand for one hour or longer with occasional stirring. Pour through a filter and use the clear filtrate. By adding more water to the precipitate of lead chlorofluoride in the beaker and stirring, more wash solution may be prepared as needed.

${ }^{27}$ Standardized by precipitating a measured portion with hydrochloric acid and weighing the silver chloride.

${ }^{28}$ Standardized by comparing with the standard solution of silver nitrate under the same conditions as obtain in the method. A convenient concentration is $0.1 \mathrm{~N}$.

${ }^{29} \mathrm{~A}$ cold saturated water solution of ferric alum (free from chlorides) to which has been added sufficient colorless nitric acid to bleach the brown color of the water solution.
} 
TABLE 4.-Results obtained by the use of procedures (b) and (c)

[All results are calculated on the basis of a $0.5 \mathrm{~g}$ sample]

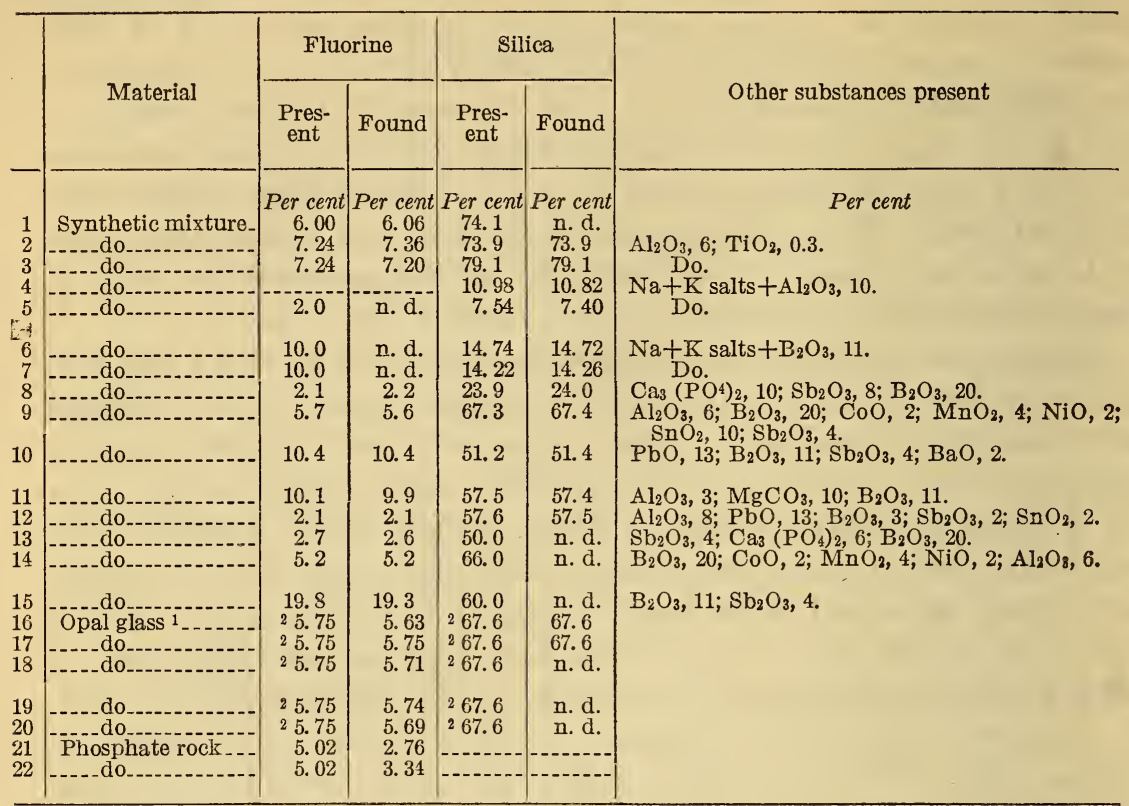

n. d.=not determined.

1 W. F. Muehlberg, chief chemist of the Newburgh Steel Works, Cleveland, Ohio, reported 5.61 per cent of fluorine and 67.8 per cent of silica on this glass the first time he used the procedures $(b)$ and $(c)$ as written. On a reanalysis he reported 5.70 per cent of fluorine and 67.6 per cent of silica.

2 Certificate value of Bureau of Standards' sample of opal glass No. 91 . These figures were obtained by averaging the results of four cooperating analysts using different types of approved methods. The figure for fluorine may be subject to an error of \pm 0.05 per cent.

\section{(d) ROUTINE METHOD FOR FLUORINE}

Fuse $0.5000 \mathrm{~g}$ of the sample (dried at $105^{\circ} \mathrm{C}$.) with $6 \mathrm{~g}$ of potassium carbonate, leach the cooled melt with hot water, and filter when disintegration is complete. Wash the insoluble residue thoroughly with hot water, and adjust the volume of the filtrate and washings to approximately $200 \mathrm{ml}$. Add $1 \mathrm{~g}$ of zinc oxide dissolved in $20 \mathrm{ml}$ of dilute nitric acid (1:9), boil for one minute with constant stirring, filter, and wash thoroughly with hot water. Proceed as in $(c)$, determination of fluorine (above).

Typical results obtained by the use of the routine method are shown in Table 5. 
TABLE 5.-Results obtained for fluorine by the routine method (d)

(All results are calculated on the basis of a $0.5 \mathrm{~g}$ sample)

\begin{tabular}{|c|c|c|c|c|}
\hline & \multirow[b]{2}{*}{ Material } & \multicolumn{2}{|c|}{ Fluorine } & \multirow[b]{2}{*}{ Other substances present } \\
\hline & & $\begin{array}{l}\text { Pres- } \\
\text { ent }\end{array}$ & Found & \\
\hline $\begin{array}{l}1 \\
2 \\
3 \\
4 \\
5\end{array}$ & \begin{tabular}{|l} 
Opal glass \\
-2 \\
$d 0$
\end{tabular} & \begin{tabular}{|r} 
Per cent \\
5.75 \\
7.12 \\
5.75 \\
5.75 \\
5.75
\end{tabular} & \begin{tabular}{|c} 
Per cent \\
5.68 \\
7.02 \\
5.83 \\
5.70 \\
5.82
\end{tabular} & $\begin{array}{l}\mathrm{FeS}_{2}, 10 \\
\mathrm{CrO}_{3}, 10\end{array}$ \\
\hline $\begin{array}{r}6 \\
7 \\
8 \\
9 \\
10\end{array}$ & $\begin{array}{l}\text { Synthetic mixture }{ }^{1} \\
d 0^{-}\end{array}$ & $\begin{array}{l}5.75 \\
2.3 \\
4.8 \\
2.3 \\
2.3\end{array}$ & $\begin{array}{l}5.59 \\
2.0 \\
4.7 \\
2.1 \\
2.2\end{array}$ & $\begin{array}{l}\mathrm{MgCO}_{3}, 20 . \\
\mathrm{Al}_{2} \mathrm{O}_{3}, 6 ; \mathrm{B}_{2} \mathrm{O}_{3}, 11 ; \mathrm{Sb}_{2} \mathrm{O}_{3}, 4 ; \mathrm{SnO}_{2}, 4 ; \mathrm{MgCO}_{3}, 6 . \\
\mathrm{Al}_{2} \mathrm{O}_{3}, 6 ; \mathrm{B}_{2} \mathrm{O}_{3}, 20 ; \mathrm{PbO}_{1} ; \mathrm{BaO}_{2} . \\
\mathrm{Al}_{2} \mathrm{O}_{3},-6 ; \mathrm{B}_{2} \mathrm{O}_{3}, 11 ; \mathrm{Sb}_{2} \mathrm{O}_{3}, 4 ; \mathrm{SnO}_{2}, 4 ; \mathrm{Mg} \mathrm{CO}_{3}, 6 . \\
\mathrm{Al}_{2} \mathrm{O}_{3}, 6 ; \mathrm{B}_{2} \mathrm{O}_{3}, 11 ; \mathrm{Sb}_{2} \mathrm{O}_{3}, 4 ; \mathrm{SnO}_{2}, 4 ; \mathrm{MgCO}_{3}, 2 .\end{array}$ \\
\hline
\end{tabular}

1 Bureau of Standards soda lime glass . No. 80 to which were added the constituents noted.

\section{SUMMARY}

1. Various methods of determining silica in the presence of fluorine have been tested, but only the procedure developed by Berzelius or some modification was found to be reliable. In the methods described the procedure of Berzelius is modified so as to eliminate (1) the long precipitation period with ammonium carbonate and the difficult filtration which follows; and (2) the slow and troublesome neutralization with small portions of nitric acid.

2. It was found that for quantities of fluorine between 0.01 and $0.10 \mathrm{~g}$ the precipitation of fluorine as lead chlorofluoride is much more convenient and rapid, and as accurate as the precipitation of a mixture of calcium fluoride and calcium carbonate followed by extraction of the latter with acetic acid.

3. The lead chlorofluoride method succeeds in the presence of moderate quantities of ammonium nitrate, and boric, chromic, sulphuric or phosphoric acids, but as now written, it is not suitable for determining fluorine in phosphate rock. The presence of much magnesium tends to yield slightly low results.

4. The effects of various other contaminants, such as oxides of tin, antimony, iron, aluminum, nickel, cobalt, manganese, and lead, are shown, and a routine method for determining fluorine is given.

Washington, June 8, 1929. 